Revista Destaques Acadêmicos, Lajeado, v. 12, n. 2, 2020. ISSN 2176-3070

DOI: http://dx.doi.org/10.22410/issn.2176-3070.v12i2a2020.2390

http://www.univates.br/revistas

\title{
OS DIREITOS FUNDAMENTAIS NO ORDENAMENTO JURÍDICO BRASILEIRO
}

\author{
Douglas Luciano de Oliveira ${ }^{1}$
}

Resumo: A pesquisa foi desenvolvida com o propósito de demonstrar a origem e a evolução dos direitos fundamentais, assim como a importância de sua positivação no texto constitucional. Objetiva-se demonstrar que os direitos fundamentais possuem o escopo de limitar e controlar o poder estatal, bem como assegurar aos cidadãos uma vida digna, através do conjunto de normas e princípios destinados a estabelecer direitos, deveres e garantias. Com a pesquisa, evidencia-se que os direitos fundamentais permanecem em constante evolução, sendo alterados consoante o desenvolvimento da sociedade, estando, atualmente, divididos no texto constitucional em direitos de primeira, segunda e terceira geração. Para a realização da pesquisa utilizou-se do método dedutivo-bibliográfico, fazendo-se intensa revisão bibliográfica de conceituados doutrinadores que já abordaram o tema. Como resultado, constata-se a consolidação dos direitos fundamentais através da atual Constituição Federal, e a necessidade da observância dos preceitos constitucionais lá dispostos por parte de todos. Conclui-se que a efetivação dos direitos fundamentais depende da conscientização e observância do texto constitucional, tornando-os, desta forma, efetivos instrumentos para o bem estar social.

Palavras-chave: Direitos Fundamentais. Origem. Evolução. Positivação. Eficácia.

\section{Introdução}

Os direitos fundamentais previstos na Constituição Federal/88 destinam-se a estabelecer direitos, garantias e deveres aos cidadãos e também ao Estado, normatizando as noções básicas e centrais que regulamentam a vida social, política e jurídica dos cidadãos que vivem no país.

1 Graduação em Direito pela Universidade de Franca, Franca/SP, pós-graduação lato sensu em Direito Constitucional e em Direito Empresarial, ambos pelo Centro Universitário Cidade Verde, Maringá/PR. Advogado regularmente inscrito nos quadros da Ordem dos Advogados do Brasil de São Paulo (OAB/SP), atuante na área do direito Empresarial e direito Bancário. 
Importante mencionar que as normas relativas aos direitos fundamentais e individuais são de eficácia e aplicabilidade imediata, conforme observamos disposto ao artigo $5^{\circ}, \S 1^{\circ}$ da Constituição Federal/88.

Os direitos fundamentais podem ser classificados em direitos de primeira, segunda e terceira geração; sendo os de primeira geração relativos aos direitos individuais, civis e políticos, os de segunda geração referentes aos direitos sociais, econômicos e culturais, e, por fim, os direitos de terceira geração, que se referem aos direitos de titularidade coletiva, como os direitos relacionados ao meio-ambiente sadio, a paz, o desenvolvimento, autodeterminação dos povos, dentre outros.

Por se tratarem dos direitos mais básicos dos cidadãos, a importância dos direitos fundamentais decorre da própria necessidade da vida inserida em um contexto social, ou seja, são inerentes a vida em sociedade, ao passo que tais direitos representam as liberdades públicas, que por força constitucional tem sua observância imposta ao Estado, impondo a este o dever de proteger e resguardar os direitos básicos dos cidadãos.

Os direitos fundamentais são alterados conforme o desenvolvimento da sociedade, e ao longo do tempo passaram por diversos estágios de evolução.

Necessário destacar a importância da força normativa da Constituição Federal/88 na defesa dos direitos fundamentais, posto que através da supremacia constitucional, temos à efetivação dos direitos fundamentais lá expostos, sendo certo que a Magna Carta somente será eficaz se estiver de acordo com a realidade política e social do país.

Não podemos deixar de mencionar que a Constituição Federal de 1988, foi um marco nos direitos dos cidadãos, coletiva e individualmente, por garantir liberdades civis e impor deveres do Estado.

Os direitos fundamentais são em verdade uma construção histórica, variando de acordo com a época e lugar, e permanecem em constante evolução.

Os direitos fundamentais surgiram a partir da positivação dos direitos humanos, os quais correspondem a direitos naturais, que tiveram seu reconhecimento pelas legislações positivadas.

Podemos dizer que os direitos fundamentais decorrem da própria natureza humana, daí seu caráter inviolável, intemporal e universal. São os direitos do ser humano, expressos na esfera do direito constitucional em um estado democrático de direito, sendo indispensáveis ao convívio harmonioso da sociedade.

O objetivo de estudar os direitos fundamentais e a sua evolução histórica no ordenamento jurídico brasileiro é entender melhor quais os bens jurídicos protegidos, bem como sua imensurável importância para a vida em sociedade, conforme será mostrado no corpo da pesquisa. 
O trabalho é composto por quatro capítulos, começando com uma breve introdução, exposição sobre o surgimento, definições, a evolução histórica dos direitos fundamentais, a previsão na Constituição Federal de 1988 e, por fim, a importância de sua rigorosa observância, por parte do Estado e de todos os cidadãos.

Este trabalho teve por objetivo demonstrar que os direitos fundamentais decorrem da própria natureza humana, e possuem o intuito de sempre proteger a pessoa humana e garantir os seus direitos mais primordiais.

O método de estudo utilizado foi o hipotético dedutivo, com o amplo estudo de vários livros e artigos de diversos estudiosos e doutrinadores no campo dos direitos fundamentais. Sempre buscando colher informação e obter conhecimento para uma melhor e mais profunda exposição sobre o tema.

\section{A origem e evolução dos direitos fundamentais}

Os direitos fundamentais correspondem a verdadeiros direitos naturais, que nascem da própria condição humana, e tiveram seu reconhecimento pelas legislações positivas. Assim, podemos dizer que os direitos fundamentais são os direitos do ser humano, positivados na esfera do direito constitucional e infraconstitucional, em um estado democrático de direito.

Os direitos fundamentais surgiram com a finalidade de limitar e controlar o poder do Estado, coibindo abusos, bem como assegurando aos cidadãos de um modo geral uma vida mais digna. Tais direitos estão em constante evolução e transformação, e são alterados consoante o desenvolvimento da sociedade.

Importante mencionar que, os direitos fundamentais possuem diversas nomenclaturas, tais como, direitos do homem, direitos humanos, além de direitos fundamentais.

O Código de Hamurabi é considerado o primeiro conceito de lei escrita conhecido, sendo este um conjunto de leis criadas na Mesopotâmia, pelo rei Hamurabi.

O Código de Hamurabi é baseado na lei de talião, "olho por olho, dente por dente", a qual previa que para cada ato considerado atentatório às leis haveria uma punição, a qual acreditavam ser proporcional ao ato criminoso cometido.

Mencionado código tinha por objetivo defender a vida e o direito de propriedade, e contemplava a honra, a dignidade, a família e a supremacia das leis em relação aos governantes.

Após o Código de Hamurabi, diversos outros códigos de condutas foram criados, sendo, por vezes, baseados em princípios religiosos ou em ideais libertárias, como a Revolução Francesa, e, ainda, a Declaração Universal dos Direitos do Homem, dentro outros códigos normativos, os quais visavam 
proteger o indivíduo contra o abuso do poder estatual, bem como garantir o mínimo a uma vivência com dignidade.

Neste sentido, Alexandre de Moraes:

"Os direitos humanos fundamentais, em sua concepção atualmente conhecida, surgiram como produto da fusão de várias fontes, desde tradições arraigadas nas diversas civilizações, até a conjugação dos pensamentos filosóficos-jurídicos, das ideias surgidas com o cristianismo e com o direito natural. (...) Assim, a noção de direitos fundamentais é mais antiga que o surgimento da ideia de constitucionalismo, que tão somente consagrou a necessidade de insculpir um rol mínimo de direitos humanos em um documento escrito, derivado diretamente da soberana vontade popular." (MORAES, 2011, p. 2-3).

Desta forma, temos claro que os direitos fundamentais decorrem de lutas de toda a sociedade, e busca proteger e impor, sob pena de sanção, o respeito e a preservação dos direitos humanos mais primitivos e primordiais.

\section{Os direitos fundamentais na Constituição Federal de 1988}

Os Direitos Fundamentais da Constituição Federal de 1988 referem-se a um conjunto de dispositivos contidos na Magna Carta destinados a estabelecer direitos, garantias e deveres aos cidadãos; normatizando as noções básicas e centrais que regulamentam a vida social, política e jurídica dos cidadãos que vivem no país.

Tais normas, que consubstanciam os direitos fundamentais e individuais, possuem eficácia e aplicabilidade imediata, conforme exposto no artigo $5^{\circ}, \S 1^{\circ}$ da Constituição Federal vigente, in verbis: "Art. $5^{\circ}, \S 1^{\circ}$ As normas definidoras dos direitos e garantias fundamentais têm aplicação imediata." (CONSTITUIÇÃO DA REPÚBLICA FEDERATIVA DO BRASIL, 1988, p. 6).

Vale elucidar que os direitos fundamentais são os direitos humanos positivados na Constituição Federal, assim se diferenciando dos direitos humanos que são ligados a liberdade e a igualdade, que estão positivados no plano internacional. Note-se que o conteúdo dos dois é essencialmente o mesmo, sendo o que os difere o plano em que estão legalmente previstos.

Os direitos fundamentais, liberdades públicas ou, ainda, direitos humanos, tal qual previsto em nossa Constituição Federal/88, são definidos como conjunto de direitos e garantias do ser humano, cuja finalidade principal é o respeito a sua dignidade, com proteção ao abuso do poder estatal e a garantia das condições mínimas de vida e desenvolvimento do ser humano, isto é, garantir ao ser humano o respeito à vida, à liberdade, à igualdade e a dignidade, em prol do livre desenvolvimento de sua personalidade. 
Não podemos deixar de mencionar que a Constituição Federal de 1988, foi um grande marco nos direitos dos cidadãos, por garantir liberdades civis e impor deveres e limitações ao poder do Estado.

A Constituição Federal/88, logo em seu início, deixou claro a importância que visava atribuir aos direitos fundamentais, posto que já em Título II, denominado "Dos Direitos e Garantias Fundamentais" (artigo $5^{\circ}$ ao artigo 17), passou a estabelecer medidas que visam limitar o poder do Estado, bem como garantir condições mínimas ao desenvolvimento dos cidadãos e da sociedade em que este se insere.

Assim, resta evidente a importância dos direitos fundamentos, a qual decorre da própria natureza humana e da vida em sociedade, bem como que a Constituição Federal/88 atribuiu a estes direitos a merecida importância e proteção legal, por serem simplesmente indispensáveis ao convívio harmonioso.

No sentido, temos o ensinamento de José Afonso da Silva:

"O reconhecimento dos direitos fundamentais do homem, em enunciados explícitos das declarações de direitos, é coisa recente, e está longe de se esgotarem suas possibilidades, já que cada passo na etapa da evolução da Humanidade importa na conquista de novos direitos. Mais do que conquista, o reconhecimento desses direitos caracteriza-se como reconquista de algo que, em termos primitivos, se perdeu, quando a sociedade se dividira entre proprietários e não proprietários." (SILVA, 1992, p.137).

Os direitos fundamentais previstos na atual Constituição Federal podem ser classificados em direitos de primeira, segunda e terceira geração. Vejamos:

\subsection{Dos direitos fundamentais de primeira geração}

A primeira geração de direitos fundamentais refere-se aos direitos individuais, civis e direitos políticos, que visam garantir a defesa do indivíduo perante o Estado, garantindo a liberdade diante da limitação do poder estatal.

Podemos chamá-la de liberdade negativa, visto que impõe ao Estado um dever de abstenção.

\subsection{Dos direitos fundamentais de segunda geração}

São direitos sociais, econômicos e culturais, garantidos através da imposição à prestação de uma atividade estatal, voltada à proteção da dignidade da pessoa humana, com a satisfação das necessidades mínimas das pessoas, tais como os direitos ao trabalho, o amparo diante de situação de doença, a seguridade social, dentre outros.

Trata-se de liberdade positiva, visto que exige do Estado a prestação de uma atividade, em prol do cidadão. 


\subsection{Dos direitos fundamentais de terceira geração}

Por fim, os direitos de terceira geração são aqueles que tratam dos direitos de titularidade coletiva, ou seja, dos direitos difusos e coletivos, que compreendem o direito ao meio ambiente sadio, a qualidade de vida, a paz, a defesa do consumidor, dentre outros.

Sua importância decorre do fato de que o homem vive inserido em uma coletividade, gerando, desta forma, direitos decorrentes da vida em sociedade.

\section{Considerações Finais}

Após a exposição do tema feita nos capítulos que compõem o presente artigo, pode-se concluir que os direitos fundamentais nada mais são do que a incorporação dos direitos naturais do ser humano ao ordenamento jurídico de um estado democrático de direito, como o Brasil.

Graças à Constituição Cidadã (CF/88), os direitos fundamentais indispensáveis para exercício da cidadania passaram a ter o merecido destaque em nosso ordenamento jurídico, impondo garantias aos cidadãos e deveres ao Estado.

Há que ressalvar porém que não basta apenas que estes direitos sejam positivados no bojo da Constituição Federal, é necessário que os direitos fundamentais sejam rigorosamente observados por todos, principalmente pelo ente estatal, para que se tenha efetividade na proteção almejada.

Importante destacar também a importância da força normativa da Constituição Federal/88 no ordenamento jurídico vigente, visto que somente através da supremacia constitucional teremos à efetivação dos direitos fundamentais lá expostos.

A efetivação dos direitos fundamentais somente será atingida mediante a conscientização, fiscalização e a punição dos que desrespeitam a Magna Carta, além da necessária elaboração de normas infraconstitucionais que possibilite que os direitos e garantias previstos na Constituição Federal/88 alcance os objetivos pretendidos.

Conclui-se que a Constituição Federal/88, merecidamente reconhecida como a Constituição Cidadã, atribuiu aos direitos fundamentais o merecido destaque, ante a natural importância destes para a vida em sociedade, impondo diversas garantias aos cidadãos, bem como deveres ao Estado, restando claro que para garantir a eficácia dos direitos fundamentais, se faz necessária a estrita observância dos mandamentos constitucionais, marco de cidadania, que garantiu aos cidadãos as liberdades civis e impôs ao Estado, dentro outras obrigações, o dever por zelar por tais liberdades. 


\section{Referências}

BRASIL. Constituição da República Federativa do Brasil. Brasília: Senado Federal, 1988.

MARMELSTEIN, George. Curso de direitos fundamentais. 7. ed. - São Paulo: Atlas, 2018 .

MELLO, Celso Antônio Bandeira de. Curso de Direito Administrativo. 8. ed. São Paulo: Malheiros, 1996.

MORAES, Alexandre de. Direitos humanos fundamentais. $9^{a}$ ed. São Paulo: Atlas, 2011.

PEREIRA, Jane Reis Gonçalves. Interpretação constitucional e direitos fundamentais. 2. ed. - São Paulo: Saraiva, 2018.

SARMENTO, Daniel. Direitos Fundamentais e Relações Privadas. Rio de Janeiro: Lumen Juris, 2010.

SAYEG, Ricardo Hasson; BALERA, Wagner. O capitalismo humanista. Petrópolis: KBR, 2011.

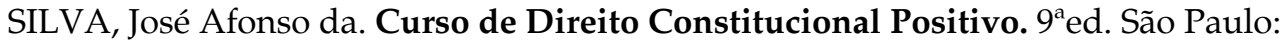
Malheiros, 1992.

TAVARES, André ramos. Curso de Direitos Constitucional. 2 ed. São Paulo: Saraiva, 2004. 